\title{
Student perceptions and mobile technology adoption: implications for lower-income students shifting to digital
}

\author{
Audrey Antee ${ }^{1}$ (D) \\ Accepted: 22 October 2020 / Published online: 30 November 2020 \\ (c) Association for Educational Communications and Technology 2020
}

\begin{abstract}
This paper responds to Joo et al. (Educational Technology Research and Development 64:611-630, 2016) study of the factors predicting South Korean online students' use of a mobile learning management system (m-LMS). The findings show students' continuous intention and their actual usage have implications for how faculty and institutions may need to promote the usefulness of mobile technology for students to accept and adopt the technology. This would be particularly relevant for lower income students with limited digital literacy skills and limited access. For many students, mobile technology is the only means through which they can persist in taking courses while institutions offer classes primarily in online modalities during the COVID-19 pandemic.
\end{abstract}

Keywords Mobile technology $\cdot$ Mobile learning $\cdot$ mLearning perceptions $\cdot$ Higher education · Digital literacy $\cdot$ Equity

\section{Introduction}

Joo et al.'s (2016) study focused on understanding factors that contributed to students' technology acceptance process. In an analysis of the qualities that predict online university students' use of a mobile learning management system (m-LMS), Joo et al. (2016) found that students' perceived usefulness and their satisfaction with the m-LMS predicted their continuous intention to use the mobile system instead of accessing the LMS on a computer. In other words, students who were satisfied with the mobile interface for their school's online learning management system and students who believed the mobile interface was useful were more likely to keep using that mobile system, even though they had the option to access their courses on a computer or laptop. From an inclusivity perspective, these results are relevant to understanding factors that may affect the ease with which students adopt mobile technology if they only have access to a mobile technology and are limited in digital literacy skills.

Audrey Antee

a.antee@fscj.edu

1 Florida State College at Jacksonville, 101 W State St., Jacksonville, FL 32202, USA 


\section{Overview of the study}

Joo et al. (2016) examined the following variables: perceived ease of use, perceived usefulness, students' expectation of technology use compared to its actual performance (expectation-confirmation), satisfaction, and actual usage of an m-LMS. The authors used information technology acceptance models, such as the Technology Acceptance Model and the Expectation-Confirmation Model, placing an emphasis on students' interactions with mobile technology.

While the researchers hypothesized that students' perceived ease of use of the m-LMS would relate to continuous intention, the results showed perceived ease of use did not predict students' continuous intention, but perceived ease of use did predict students' perceived usefulness, and continuous intention predicted students' actual usage of the m-LMS. Also, if students' expectations for using the m-LMS were met (expectation-confirmation), and if they perceived that use of the m-LMS would enhance their academic performance, they were satisfied with the learning experience. Their actual use of the system reflected these perceptions.

The authors conclude that students' perceived ease of use may not impact their continuous intention to use mobile technology and, therefore, does not necessarily predict their actual use. Essentially, believing mobile technology is easy to use wouldn't necessarily impact whether students persist in using it. If students believe the technology will have a positive impact on their learning experience, they will keep using it. Joo et al. (2016) also indicate that a key factor in this conclusion maybe the setting of the study. The participants attended an online university in South Korea, a country with an advanced information and communications technology (ICT) infrastructure. As a result of the setting and sampling, participants may have had digital literacy skills, been more familiar with mobile technology, and had positive experiences with mobile technology prior to the study (Joo et al. 2016).

\section{Inclusivity and mobile learning adoption}

Because of the participants' potential familiarity with online learning and mobile technology, Joo et al. (2016) suggest that future studies examine diverse populations and actual use of mobile technology to gain a better picture of student adoption in other countries. A person's income can affect the type of mobile device he or she can afford, and developing nations may not have an advanced ICT industry. A country's ICT infrastructure and an individual's income (in a developed or developing nation) may be critical factors in a person's experiences and knowledge of mobile learning and mobile technology.

Though computers and mobile technology are ubiquitous, in the U.S. education system, minority students often come to college with fewer digital skills related to academics and less experience with technology in general (Kuo and Belland 2016). In developed nations, these students are exposed to fewer digital literacies at home, including basic skills such as accessing email, resulting in "significant implications in terms of education equality" (Darvin 2018, p. 27). According to Moore et al. (2018), in the U.S., 1 in 5 high school students surveyed reported only having access to one device at home and met the criteria for being "underserved," meaning they had at least one or more of the following characteristics: low income, first generation student, and a minority. 
In developing nations, gender may impact digital literacy, with women being less likely to use technology, and in some nations, less of an emphasis on ICT in education overall compared to developed nations affects digital literacy among men and women (Hamutoglu et al. 2020; Kaliisa and Picard 2019). Several developing nations are experiencing rapid growth in access to mobile devices and increases in access, but parts of sub-Saharan Africa, South Asia, the Middle East and North Africa still lack access to mobile Internet connectivity, particularly in rural areas (Kaliisa and Picard 2019). Despite the significant differences between the students studied in Joo et al. (2016) and populations where social and economic disparities impact digital literacies, Joo et al. (2016) provide evidence that students may persist in using mobile technology for learning though using a mobile device may be difficult.

\section{Implications for current and future practices}

Digital literacy deficits and limited access to a mobile device or the Internet can be difficult to overcome in situations where students, currently attending a university or college, must transition from face-to-face instruction to online. Joo et al.'s (2016) findings affirm that student perceptions can predict continuous intention and actual usage of a m-LMS. Perhaps, despite students' potential digital literacy deficits or limitations with mobile device use, instructors and institutions that take steps to demonstrate the positive impact mobile technologies can have on students' learning may have a positive influence over students' persistence in using mobile devices to complete courses that are only available online.

Joo et al. (2016) note how some of the affordances associated with mobile learning, specifically social interactivity, were not built into the m-LMS, yet Grant (2019) observes that mobile learning affordances such as "portability, social interactivity, context sensitivity, connectivity, and individuality" could impact students' acceptance of mobile technology and mobile learning (p. 369). Students' perceived usefulness and satisfaction with mobile learning can be impacted by whether courses are designed with mobile learning and mobile devices in mind (Baldwin and Ching 2020; Grant 2019; Hembrough and Jordan 2020).

Institutions and their faculty can contribute to students' perceived usefulness and satisfaction by ensuring that course design aligns with mobile device functionality (small screens, course materials incompatible with mobile devices, no external keyboard, etc.) while maintaining learning activities that would be comparable to face-to-face learning (Baldwin and Ching 2020; Hembrough and Jordan 2020). Where possible, institutions of higher education should ensure their students have access to mobile devices, which may be more affordable than laptops, and the Internet since no access would be an insurmountable barrier to students despite their desire to persist in adopting mobile learning (Moya and Camacho 2019). Taking such steps would ideally help students complete courses in the midst of an urgent shift to digital learning, regardless of whether they may lack digital literacy or find their mobile device is a difficult means for completing their courses.

Funding No funding was received in support of this manuscript nor does Dr. Antee have personal affiliations with the authors whose research is the subject of this paper. She is also not affiliated with the Association for Educational Communications \& Technology other than holding standard membership to the organization. 


\section{Compliance with ethical standards}

Conflict of interest Dr. Antee declares that she has no conflict of interest.

Informed consent As this manuscript is a response to an article previously published in Educational Technology Research \& Development, Dr. Antee did not engage in a direct study of human participants, and therefore had no subjects from whom to gain informed consent.

\section{References}

Baldwin, S. J., \& Ching, Y. H. (2020). Guidelines for designing online courses for mobile devices. TechTrends, 64(3), 413-422. https://doi.org/10.1007/s11528-019-00463-6

Darvin, R. (2018). Social class and the unequal digital literacies of youth. Language and Literacy, 20(3), 26-45. https://doi.org/10.20360/langandlit29407

Grant, M. M. (2019). Difficulties in defining mobile learning: analysis, design characteristics, and implications. Educational Technology Research and Development, 67(2), 361-388. https://doi.org/10.1007/ s11423-018-09641-4

Hamutoglu, N. B., Gemikonakli, O., De Raffaele, C., \& Gezgin, D. M. (2020). Comparative cross-cultural study in digital literacy. Eurasian Journal of Educational Research (EJER), 88, 121-147. https://doi. org/10.14689/ejer.2020.88.6

Hembrough, T., \& Jordan, J. (2020). Creating a digital writing classroom: a mixed methods study about a first-year composition tablet initiative. International Journal of Instruction, 13(2), 567-586. https:// doi.org/10.29333/iji.2020.13239a

Joo, Y. J., Kim, N., \& Kim, N. H. (2016). Factors predicting online university students' use of a mobile learning management system (m-LMS). Educational Technology Research and Development, 64(4), 611-630. https://doi.org/10.1007/s11423-016-9436-7

Kaliisa, R., \& Picard, M. (2019). Mobile learning policy and practice in Africa: towards inclusive and equitable access to higher education. Australasian Journal of Educational Technology, 35(6), 1-14. https:// doi.org/10.14742/ajet.5562

Kuo, Y., Belland, B. (2016) "An exploratory study of adult learners' perceptions of online learning: Minority students in continuing education." Educational Technology Research and Development, 64(4), 661680. Retrieved July 28, 2020, from https://www.jstor.org/stable/24761394.

Moore, R., Vitale, D., Stawinoga, N. (2018) The Digital Divide and Educational Inequity. ACT Research Center for Equity in Learning. Retrieved July 30, 2020, from https://equityinlearning.act.org/wp-conte nt/themes/voltron/img/tech-briefs/the-digital-divide.pdf.

Moya, S., Camacho, M. (2019). What factors matter most for mobile learning adoption? International Association for Development of the Information Society. International Conference on Mobile Learning (pp. 27-34). ERIC. Retrieved July 28, 2020, from https://eric.ed.gov/?id=ED601157.

Publisher's Note Springer Nature remains neutral with regard to jurisdictional claims in published maps and institutional affiliations.

Audrey Antee has taught English Composition and Literature at FSCJ since 2011, and she has served as the Assistant Director for the Faculty Academy for Teaching and Learning since 2018. She holds a Master's degree in English Literature and a Doctorate in Curriculum and Instruction with a specialization in Educational Technology. Her research interests include collaborative learning and technology, mobile learning, and faculty use of technology and accessibility to name a few. 